\title{
Would you mind doing some modifications to the classical rhombic flap?
}

\author{
Klasik romboid flepte modifikasyonlar yapabilir misiniz?
}

\section{ه Gonca Elçin}

Hacettepe University Faculty of Medicine, Department of Dermatology, Ankara, Turkey

\section{1-Why do we need flaps in dermatologic surgery?}

Sometimes the final surgical defect is too large for primary repair, or primary repair may cause distortion of the surrounding anatomic structures. Then we need to redistribute and redirect tension vectors from the primary defect to a secondary defect. Flaps serve very well for these purposes.

\section{2-What is a transposition flap?}

Transposition flaps act in a Robin Hood-like manner. They take skin from a skin-reach area where laxity is abundant, to a skin-poor area where laxity is lacking.

Transposition flaps redirects tension vectors during closure.

3-Which is the most commonly utilized transposition flap in dermatologic surgery?

Rhombic flap. Rhombic flap was initially described by Alexander Limberg in 1946, and was published in the literature in $1963^{1}$. It is mostly used to repair defects on the cheek, temple, eyelid, nose, lip, chin and neck. However rhombic flap should not be preferred on the forehead to avoid unpleasant scars.

\section{4-How do we design a rhombic flap?}

Rhombic flap is one of the most popular transposition flaps in dermatologic surgery, which is planned as converting a circular surgical defect into a 4-sided rhombus with equal side lengths and with tip angles of $60^{\circ} \mathrm{C}$ and $120^{\circ} \mathrm{C}$. Classically an incision line, which extends from one of the obtuse angles of the rhombus with a length equal to one side of the rhombus, is drawn. This is called the leading edge. From the free end of this leading edge a second incision line is drawn as parallel and equal to the length of the near side of the rhombus. This creates a flap lobe with an angle of $60{ }^{\circ} \mathrm{C}$ at the top and a flap take-off angle of $120^{\circ} \mathrm{C}^{2}$

\section{5-Is there any disadvantage of a rhombic flap?}

Pivotal restraint may cause tip tension. The more the tension in a wound, the prominent is the final scar.

\section{6-How can we design a modified rhombic flap?}

There are plenty of modifications described for rhombic flaps $^{3}$. Lengthening the flap lobe is one practical option as shown in Figure 1. Such a modification allows a closure with less tension as shown in Figures 2-4.

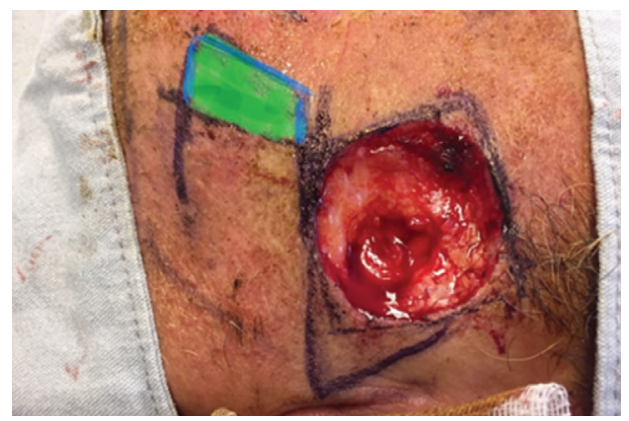

Figure 1. Lengthening the flap lobe allows a closure with minimal tip tension. The green area marks the area that has been added to the classical rhombic flap lobe. Please note that the ultimate end of such modification is a larger standing cone, which allows for a wider pivotal motion

Address for Correspondence/Yazışma Adresi: Gonca Elçin PhD, Hacettepe University Faculty of Medicine, Department of Dermatology, Ankara, Turkey Pohone.: +90 5324026699 E-mail: goncaelcin@gmail.com Received/Geliş Tarihi: 06.06.2019 Accepted/Kabul Tarihi: 13.06.2019 ORCID ID: orcid.org/0000-0001-6292-7272 


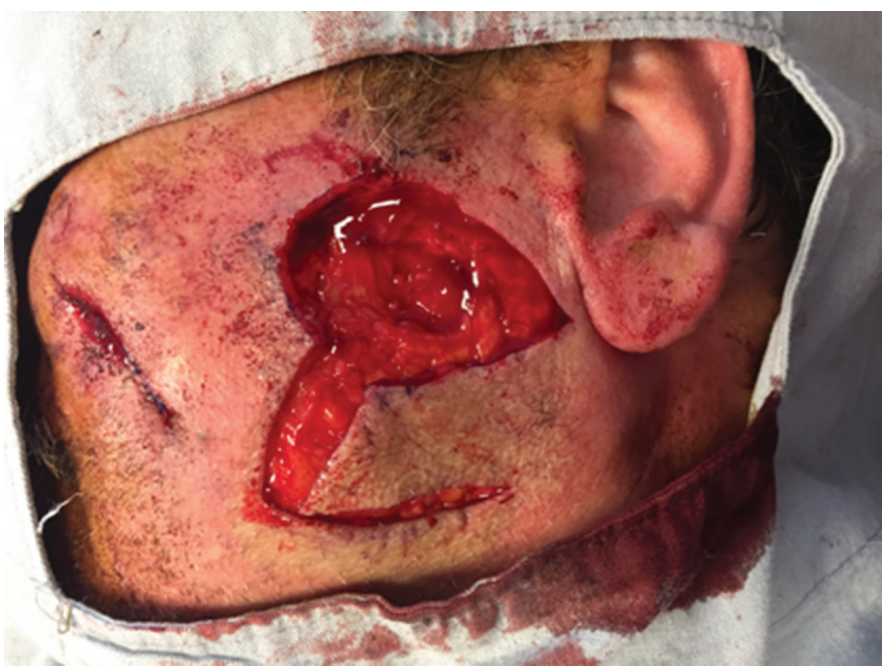

Figure 2. The standing cone is cut out and the flap lobe is ready to move

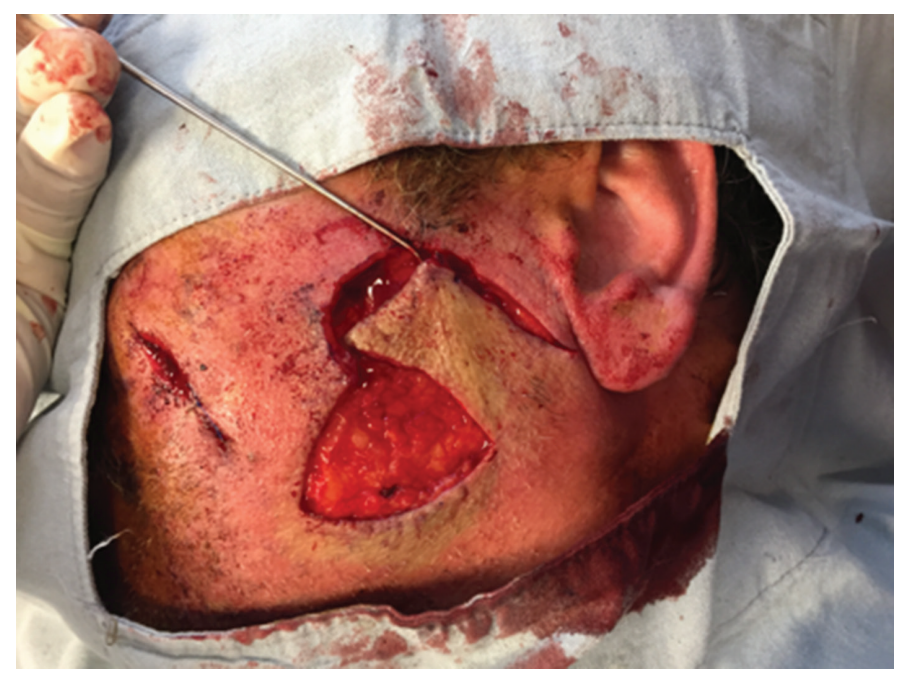

Figure 3. The flap lobe is in its final position without any tension

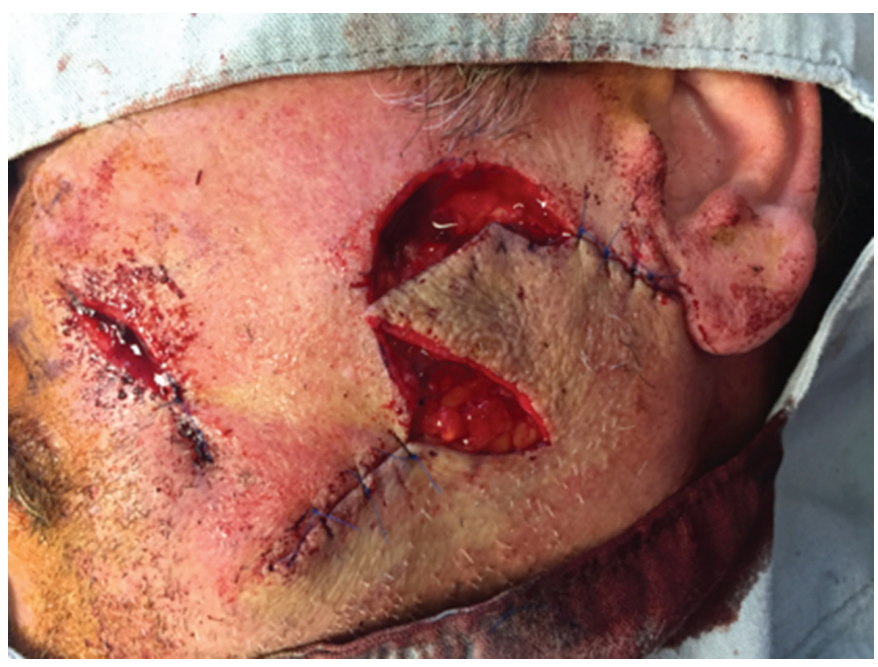

Figure 4. Secondary defects have been closed first

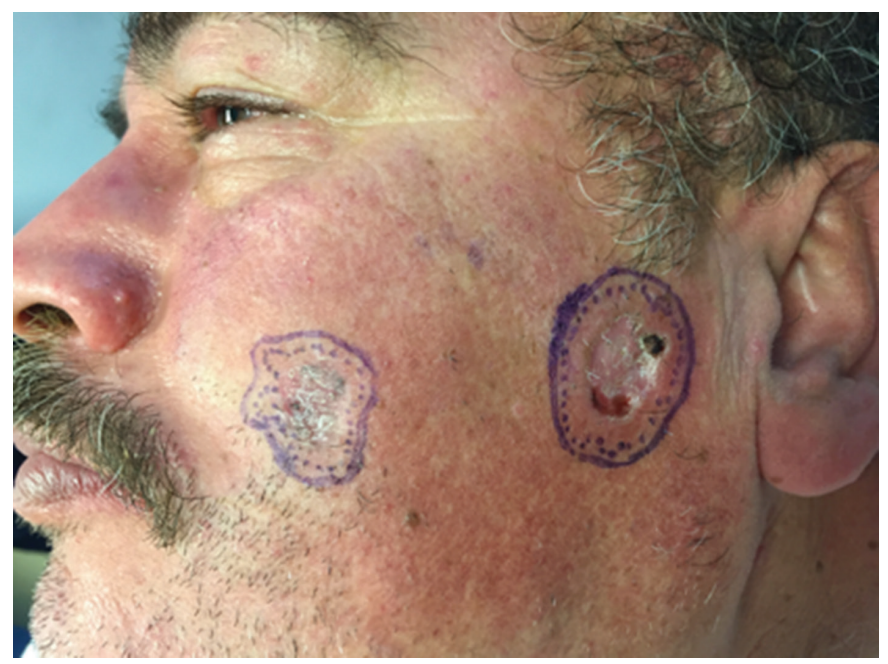

Figure 5. The pre-operative photograph of the patient. He had 2 nodulo-ulcerative BCCs of more than $1 \mathrm{~cm}$ diameter on his left chick. Mohs Micrographic Surgery was used to reach 100\% tumor free surgical margins for both tumors

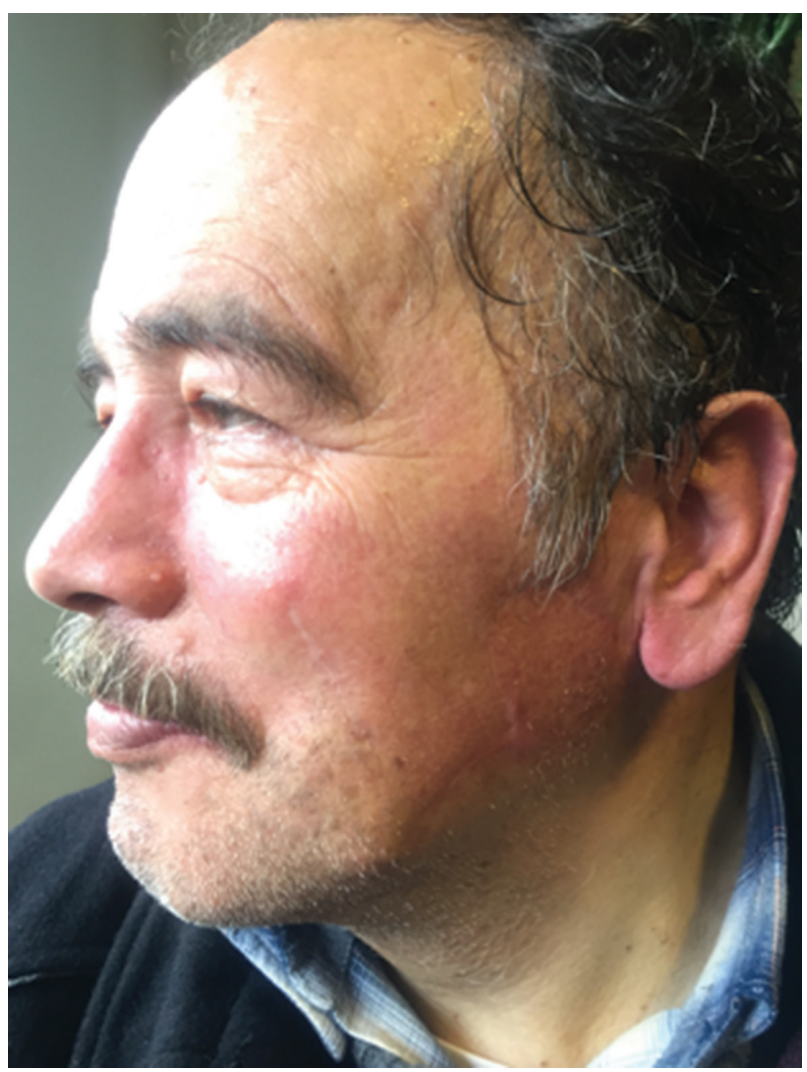

Figure 6. Six months after the procedure

The pre-operative picture of this patient with 2 relatively large basal cell carcinomas on the left chick is shown in Figure 5. Figure 6 shows the patient at postoperative $6^{\text {th }}$ month with a favourable cosmetic result. Please note that for skin cancers the use of complex surgical repairs such as flaps is recommended only after reaching 100\% tumor free surgical margins. Mohs surgery is a pathologic technique that serves for $100 \%$ surgical margin control which was used to treat 
this patient's both tumors on the left chick. The patient allowed his photographs taken for his skin disease to be used for training, research and publication purposes.

\section{References}

1. Limberg AA. Design of local flaps. Modern trends of plastic surgery. Ed. Gibson T. 1966, London, Butterworth-Heinemann, 1966;38-61.
2. Bhatia A, Rohrer TE: Transposition flaps. Flaps and grafts in dermatologic surgery. Eds. Rohrer TE, Cook JL,Nguyen TH, Mellette JR. 2007, Philadelphia, Saunders Elsevier, 2007;79-90.

3. Transposition flaps. In: Facial Flap Surgery. Eds. Goldman GD, Dzubow LM, Yelverton CB. 2013, New York, McGrawHill, 2013;42-61. 